\title{
Spectroscopic and Microscopic Characterization of Volcanic Ash from Puyehue-(Chile) Eruption: Preliminary Approach for the Application in the Arsenic Removal
}

\author{
Irma Lia Botto, ${ }^{1}$ María Elena Canafoglia, ${ }^{1}$ Delia Gazzoli, ${ }^{2}$ and María José González ${ }^{1,3}$ \\ ${ }^{1}$ CEQUINOR Facultad de Ciencias Exactas (CONICET La Plata-UNLP), 47 y 115, 1900 La Plata, Argentina \\ ${ }^{2}$ Dipartimento di Chimica, Universitá di Roma La Sapienza, Piazzale Aldo Moro 5, 00185 Roma, Italy \\ ${ }^{3}$ INREMI Facultad de Ciencias Naturales y Museo (CICPBA-UNLP), 64 y 120, 1900 La Plata, Argentina \\ Correspondence should be addressed to Irma Lia Botto; botto@quimica.unlp.edu.ar
}

Received 17 May 2013; Revised 17 July 2013; Accepted 2 August 2013

Academic Editor: Niksa Krstulovic

Copyright (c) 2013 Irma Lia Botto et al. This is an open access article distributed under the Creative Commons Attribution License, which permits unrestricted use, distribution, and reproduction in any medium, provided the original work is properly cited.

\begin{abstract}
Volcanic ash from Puyehue Cordon Caulle Volcanic Complex (Chile), emitted on June 4, 2011, and deposited in Villa La Angostura at $\sim 40 \mathrm{~km}$ of the source, was collected and analyzed by Raman spectroscopy, optical and scanning electron microscopy (SEM-EDS), Xray diffraction (XRD), surface area (BET), and chemical analysis (ICP-AES-MS technique). The mineralogical and physicochemical study revealed that the pyroclastic mixture contains iron oxides in the form of magnetite and hematite as well as pyroxene and plagioclase mineral species and amorphous pumiceous shards. Carbonaceous material was also identified. Physicochemical techniques allow us to select two representative samples (average composition and Fe-rich materials) which were used to analyze their performances in the adsorption process to remove arsenic from water. Additional iron activation by means of ferric salts was performed under original sample. Results showed that the low-cost feedstock exhibited a good adsorption capacity to remove the contaminant, depending on the iron content and the water $\mathrm{pH}$.
\end{abstract}

\section{Introduction}

The south-andes Cordillera is one of the world regions with intense volcanic and tectonic activity. The last eruption, started on June 4, 2011, was associated with the activity of Puyehue Cordon Caulle Volcanic Complex (PCCVC), Chile, located at $40^{\circ} 34^{\prime} 57^{\prime \prime} \mathrm{S}-72^{\circ} 06^{\prime} 53^{\prime \prime} \mathrm{W}$, emitting more than $5 \times$ $10^{6} \mathrm{~m}^{3}$ of pyroclastic material [1]. The dominance of "westerlies" regional winds was responsible for the dispersion and sedimentation of ash on a large region along eastern South America, particularly Patagonia and Argentine Pampean Plain.

Although the preliminary characterization of the ash showed a composition predominantly rhyolitic, the ejected material was composed of different types of particles. Eruption stages and distance from the volcanic source affected the chemical composition of the mixture, but, in general, the material was nearly amorphous to the XRD, with a texture characterized by the presence of vesicles. However, in the early stages of the volcanic event a dark (brownish-black) and heavy particulate matter, with variable size and hardness, was emitted [2].

The application of the volcanic ash depends on several factors such as the mineralogy and chemical composition [35], so that the thorough understanding of physicochemical properties of the phases present in the feedstock can play a decisive role in the evaluation of their technological potential.

As for arsenic removal from contaminated aqueous medium, different iron-rich minerals can be used $[6,7]$; the chemical affinity between $\mathrm{Fe}-\mathrm{O}-\mathrm{H}$-arsenate groups can be applied to develop low-cost technologies, particularly useful in rural zones without any other water sources for human consumption $[8,9]$. In fact, the presence of arsenate $(\mathrm{V})$ is widespread in groundwater, reaching values exceeding those recommended by the WHO $\left(10 \mu \mathrm{g} \mathrm{L}^{-1}\right)$, situation that leads to many chronic health problems [10]. In this sense, Argentina is one of the most affected countries of South America [11], where the contamination has become a serious problem. 
The aim of this work is to study the physicochemical behavior of the ash and tephras deposited in Villa La Angostura $\left(40^{\circ} 45^{\prime} 48^{\prime \prime} \mathrm{S}-71^{\circ} 38^{\prime} 46^{\prime \prime} \mathrm{W}\right)$ and collected five months after the eruption and the need to approach the potential application (in the original form and activated with ferric phases) to remove arsenic from groundwater.

Scanning electron microscopy (SEM-EDS), optical measurements, surface (BET) and chemical analysis (by inductively coupled plasma (ICP) technique for major and trace elements), X-ray diffraction, and Raman spectroscopy were directed to the mineralogical and chemical characterization of the material.

\section{Materials and Methods}

The material from Villa La Angostura (about $40 \mathrm{~km}$ from the volcanic source), having particle sizes between 10 and $3000 \mu \mathrm{m}$, was dried at $100^{\circ} \mathrm{C}$ and identified as pyroclastic material (PM). No thermal transformations were observed in the $60-100^{\circ} \mathrm{C}$ range. The humidity elimination $(\sim 30 \%$ of water) was necessary to perform the physicochemical characterization. The selection of the mixture components was done with the aid of the binocular microscope. Glass and light shards with vesicular microcavities were identified as pumiceous-type material (PT), whereas the dark particles, also vesiculated, were named as scoria-type (ST) material. Lithoclasts of size lower than the PT and ST materials, of intense black color and smooth uniform surfaces, were identified as rounded blocks (RB). The material densities followed the sequence $\mathrm{RB}>\mathrm{ST}>\mathrm{PT}$. The former presents also a magnetic behavior. Additional optical measurements were useful to reveal the difference between crystalline and vitreous particles.

PT and ST materials were washed with ethanol by the ultrasonic technique to facilitate the separation of very thin adhered particles and then dried at $80^{\circ} \mathrm{C}$.

Scanning electron microscopy and electron diffraction spectroscopy (SEM-EDS) measurements were performed in an ESEM (FEI Quanta 200), with tungsten filament and an ETD (high vacuum secondary electron) detector. Microanalysis was carried out with an EDAX Detector Apollo 40. Chemical results were expressed as \% oxides.

Chemical analysis was performed by ICP-AES for major elements (expressed as \% oxides) and ICP-MS for trace Rare Earth Elements (REE) (in ppm) (ALS Chemex Lab., Canada). The geochemical behavior was analyzed from variance diagrams of REE normalized to chondrite igneous system.

The BET surface area was measured by $\mathrm{N}_{2}$ adsorption using a Micromeritics ASAP 2020 Automated BrunauerEmmett-Teller Sorptometer.

$\mathrm{X}$-ray diffraction patterns for crystalline phase analysis were collected with a Philips PW 1710 diffractometer, $\mathrm{Cu} \mathrm{K} \alpha$ Ni-filtered radiation.

Raman spectroscopic analyses were carried out with inVia Renishaw micro-Raman spectrometer equipped with an air-cooled CCD detector and edge filters. A $785.0 \mathrm{~nm}$ emission line from a diode laser was focused on the sample by a Leica DLML microscope, using $5 \mathrm{x}$ or $20 \mathrm{x}$ objectives.
The power of the incident beam is about $5 \mathrm{~mW}$. Five $10 \mathrm{~s}$ accumulations were generally acquired for each sample. The resolution was $2 \mathrm{~cm}^{-1}$, and the spectra were calibrated using the $520.5 \mathrm{~cm}^{-1}$ line of a silicon wafer. Spectral analysis was done by background subtraction and curve fitting.

Preliminary tests for As removal by adsorption were carried out at room temperature $\left(20^{\circ} \mathrm{C}\right)$ using PM material (up to $3000 \mu \mathrm{m}$ ) and ST material (about 1000-2000 $\mu \mathrm{m}$ ) without grinding. The chemical activation of PM material by means of ferric chloride to give PMA sample was made following the procedure reported by Chen et al. [12]. The batch experiments to study the removal of As from solution were carried out by reacting $10 \mathrm{~g}$ solid with $100 \mathrm{~mL}$ contaminated water. The arsenic-containing solution of $134 \mu \mathrm{g} \mathrm{L}^{-1}$, simulating conditions of affected groundwater in Buenos Aires province [13], was obtained from hydrated sodium arsenate $\left(\mathrm{Na}_{2} \mathrm{HAsO}_{4} \cdot 7 \mathrm{H}_{2} \mathrm{O}\right)$ and deionized water. The mixture was kept at room temperature for $1 \mathrm{~h}$, by stirring at $200 \mathrm{rpm}$ to ensure complete homogenization. The slurries were kept at room temperature for $24 \mathrm{~h}$. The supernatant was filtered through a $0.45 \mu \mathrm{m}$ membrane filter. The initial and final concentration of arsenic in the solution was determined by a Perkin Elmer Analyst 200 (equipped with a Perkin Elmer HGA 900 Graphite-Furnace). The As retained in the solid was calculated according to the expression:

$$
\operatorname{Re}=\frac{\left(\left[C_{0}-C_{r}\right] \times 100\right)}{C_{0}},
$$

where $\mathrm{Re}$ is the arsenate removal (\%) and $C_{0}$ and $C_{r}$ are the initial and residual (after $24 \mathrm{~h}$ ) As concentrations, expressed in $\mu \mathrm{g} \mathrm{L}^{-1}$.

The $\mathrm{pH}$ of suspensions was adjusted between 3 and 9 by using $0.1 \mathrm{M}$ solutions of $\mathrm{HCl}$ or $\mathrm{NaOH}$. The values were monitored by means of the Denver Instrument Ultrabasic Benchtop $\mathrm{pH}$ meter. In order to maintain a relatively constant ionic strength, the arsenic solutions contain $0.01 \mathrm{M} \mathrm{NaCl}$ as background electrolyte. The experiments were done by triplicate.

\section{Results and Discussion}

3.1. Physicochemical Characterization. According to the reflection microscope, the volcanic material shows a predominance (70-80\%) of pumice fragments (glass blabbing). To a lesser extent (30-20\%) crystals and crystal fragments of metal oxide and silicate phases were observed.

Figure 1(a) shows the SEM images of the ejected volcanic pyroclastic mixture (PM), whereas Figure 1(b) corresponds to the major component named pumiceous type (PT). Typical SEM images of dark particles, classified as scoria type (ST), in the original form and after ultrasonic washing $\left(\mathrm{ST}_{\mathrm{W}}\right)$ to remove fine particles (adhered at the surface and filling the vesicles), are shown in Figures 1(c) and 1(d) with the correlative images at different magnification. Black rounded blocks (RB), also at different magnification, are shown in Figure 1(e). It is possible to notice that the texture and morphology among PT, ST, and RB samples were different. 

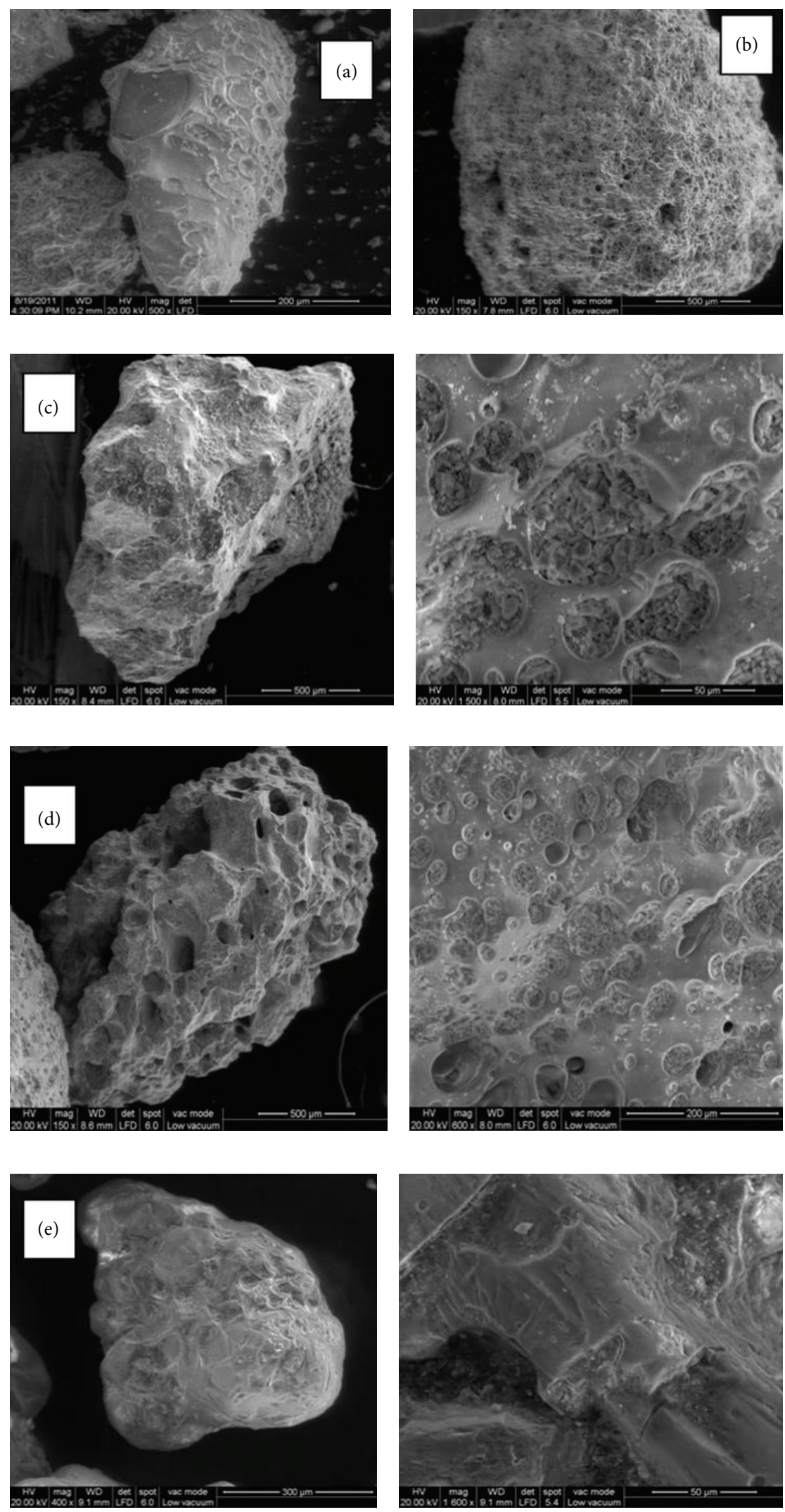

FIGURE 1: SEM micrographs of samples (a) PM, (b) PT, (c) ST, (d) $\mathrm{ST}_{\mathrm{W}}$, and (e) RB. PM: volcanic pyroclastic mixture; PT: pumiceous type; $\mathrm{ST}$ : scoria type; $\mathrm{ST}_{\mathrm{W}}$ : washed scoria type; $\mathrm{RB}$ : rounded block. 
TABLE 1: EDS data for volcanic pyroclastic mixture (PM) and selected typical components.

\begin{tabular}{|c|c|c|c|c|c|c|}
\hline$\%$ oxide & $\mathrm{PM}$ & ST & $\mathrm{ST}_{\mathrm{W}}$ & $\mathrm{RB}$ & PT & $\mathrm{PT}_{\mathrm{W}}$ \\
\hline $\mathrm{CO}_{2}$ & 4.12 & 7.30 & 6.15 & 12.56 & 3.64 & 2.44 \\
\hline $\mathrm{Na}_{2} \mathrm{O}$ & 4.65 & 4.05 & 3.44 & $\mathrm{Nd}$ & 5.58 & 5.37 \\
\hline $\mathrm{MgO}$ & 2.08 & 2.82 & 3.02 & 10.07 & 1.41 & 0.57 \\
\hline $\mathrm{Al}_{2} \mathrm{O}_{3}$ & 14.85 & 17.01 & 17.89 & 4.72 & 13.84 & 14.52 \\
\hline $\mathrm{SiO}_{2}$ & 61.25 & 54.56 & 51.60 & 37.48 & 62.76 & 68.28 \\
\hline $\mathrm{K}_{2} \mathrm{O}$ & 1.48 & 1.21 & 0.60 & $\mathrm{Nd}$ & 3.19 & 2.36 \\
\hline $\mathrm{CaO}$ & 2.75 & 4.90 & 5.61 & 3.70 & 2.52 & 1.85 \\
\hline $\mathrm{TiO}_{2}$ & 1.01 & 0.88 & 1.57 & 4.47 & 1.07 & 1.06 \\
\hline $\mathrm{Fe}_{2} \mathrm{O}_{3}$ & 7.81 & 7.27 & 10.12 & 27.00 & 5.99 & 3.55 \\
\hline
\end{tabular}

PM: volcanic pyroclastic mixture; ST: scoria type; PT: pumiceous type; RB: rounded block; w: washed.

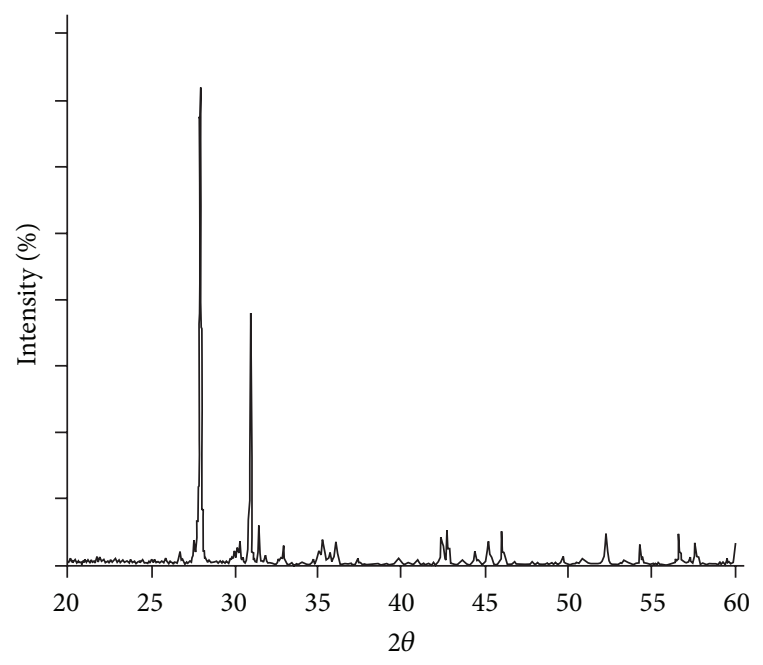

FIGURE 2: XRD pattern of ST sample (see text).

TABLE 2: Major and minor elements (expressed as \% oxides) by ICP AES.

\begin{tabular}{|c|c|c|c|}
\hline Sample & PM & $\mathrm{PT}$ & ST \\
\hline $\mathrm{SiO}_{2}$ & 67.03 & 70.30 & 60.52 \\
\hline $\mathrm{TiO}_{2}$ & 0.89 & 0.65 & 1.17 \\
\hline $\mathrm{Al}_{2} \mathrm{O}_{3}$ & 14.17 & 13.35 & 14.52 \\
\hline $\mathrm{Fe}_{2} \mathrm{O}_{3}$ & 5.58 & 4.56 & 8.92 \\
\hline $\mathrm{MnO}$ & 0.14 & 0.12 & 0.16 \\
\hline $\mathrm{MgO}$ & 1.05 & 0.56 & 2.77 \\
\hline $\mathrm{CaO}$ & 2.95 & 2.02 & 5.76 \\
\hline $\mathrm{Na}_{2} \mathrm{O}$ & 5.04 & 5.12 & 3.77 \\
\hline $\mathrm{K}_{2} \mathrm{O}$ & 2.37 & 2.52 & 1.49 \\
\hline $\mathrm{P}_{2} \mathrm{O}_{5}$ & 0.17 & 0.13 & 0.33 \\
\hline $\mathrm{Cr}_{2} \mathrm{O}_{3}$ & 0.01 & 0.01 & 0.01 \\
\hline $\mathrm{BaO}$ & 0.08 & 0.08 & 0.05 \\
\hline $\mathrm{SrO}$ & 0.02 & 0.02 & 0.04 \\
\hline LOI & 0.50 & 0.56 & 0.49 \\
\hline
\end{tabular}

PM: volcanic pyroclastic mixture; ST: scoria type; PT: pumiceous type.

Table 1 gives typical EDS results (average of ten determinations). The iron content of the samples increases in

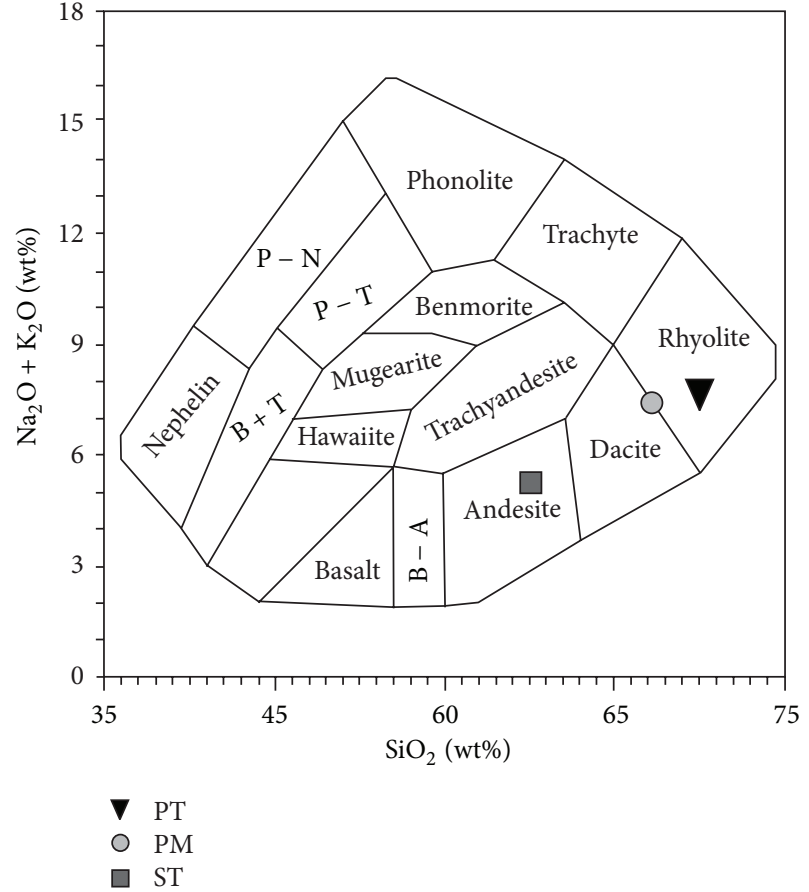

FIgURE 3: Total alkali-silica (TAS) plot for PT, PM and ST samples.

the order $\mathrm{PT}<\mathrm{ST}<\mathrm{RB}$, whereas the $\mathrm{PM}$ pyroclastic material reveals the contribution of the mixture components. Rounded blocks (RB), of intense black color, are the Fe and Ti richest samples. Dark color can be associated with the Fe(II)$\mathrm{Fe}(\mathrm{III})$ intervalence charge transfer process [14].

According to EDS results, the $\mathrm{SiO}_{2} / \mathrm{Al}_{2} \mathrm{O}_{3}$ ratio in the ST particles is near 3, value that increases to $\sim 5$ in the $\mathrm{PT}$ samples. The diminution of $\mathrm{Al}$ content can be associated with the enrichment of Si species (crystalline or glassy). Likewise, the $\mathrm{RB}$ particles are characterized by the absence of alkaline elements ( $\mathrm{K}$ and $\mathrm{Na}$ ) and the presence of $\mathrm{Mg}$ and $\mathrm{Ca}$. This fact suggests the existence of mixed valence iron oxides or related phases (magnetite-type) containing $\mathrm{Fe}, \mathrm{Mg}, \mathrm{Al}$, and Ti. The presence of $\mathrm{Ca}$ can be associated with some silicate (probably plagioclase). It is evident that the finest particles are mobilized by the ultrasonic treatment, affecting the relative 
TABLE 3: REE trace elements (expressed as ppm) by ICP MS.

\begin{tabular}{lcccccccccccccc}
\hline Sample & $\mathrm{La}$ & $\mathrm{Ce}$ & $\mathrm{Pr}$ & $\mathrm{Nd}$ & $\mathrm{Sm}$ & $\mathrm{Eu}$ & $\mathrm{Gd}$ & $\mathrm{Tb}$ & $\mathrm{Dy}$ & $\mathrm{Ho}$ & $\mathrm{Er}$ & $\mathrm{Tm}$ & $\mathrm{Yb}$ & $\mathrm{Lu}$ \\
\hline PM & 29 & 65.7 & 9 & 40 & 8.13 & 2 & 8 & 1 & 8 & 1.71 & 5.35 & 0.82 & 5.4 & 0.87 \\
PT & 31 & 69.6 & 9 & 37 & 8.57 & 2 & 8 & 1 & 8 & 1.86 & 5.45 & 0.88 & 5.8 & 0.92 \\
ST & 20 & 45.5 & 6 & 26 & 6.51 & 2 & 6 & 1 & 6 & 1.35 & 3.98 & 0.60 & 3.8 & 0.59 \\
\hline
\end{tabular}

PM: volcanic pyroclastic mixture; ST: scoria type; PT: pumiceous type.

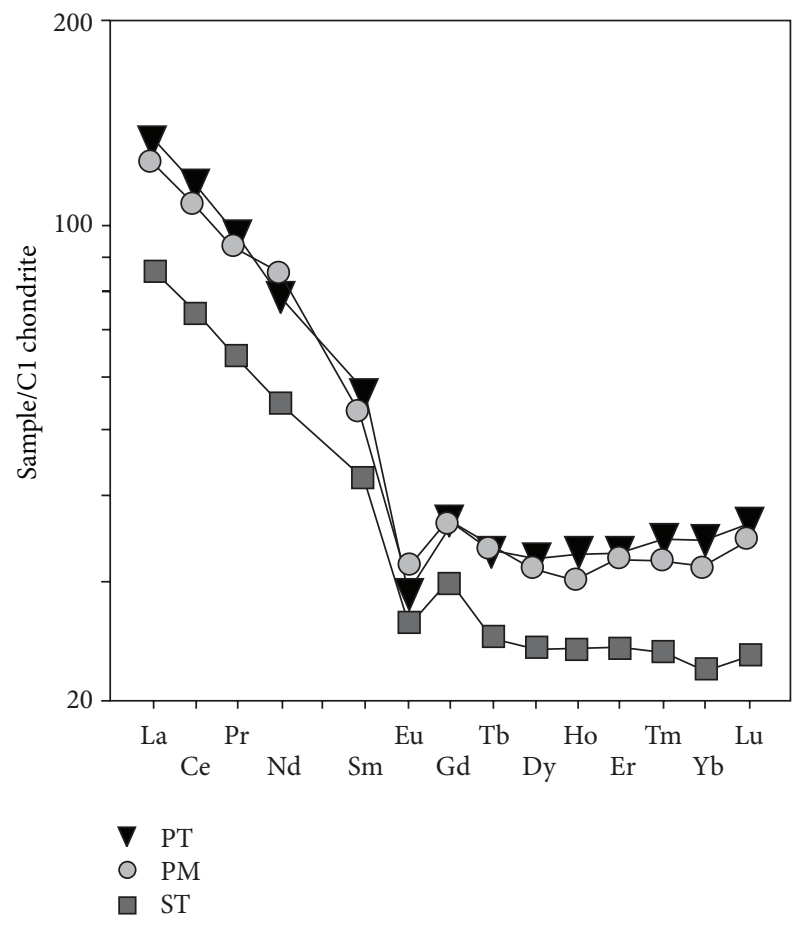

FIGURE 4: Spider diagram of REE for PT, PM, and ST samples.

$\mathrm{Si} / \mathrm{Fe}$ composition. The washing of ST samples facilitates the exposition of iron species by elimination of Si-rich particles adhered in vesicles. Finally, the presence of carbonaceous materials is observed particularly in the dark particles.

Moreover, Table 2 presents the bulk chemical analysis by ICP-AES (major and minor elements), whereas Table 3 gives the ICP-MS data for REE trace elements. Comparison between bulk and EDS chemical data suggests that iron phases are concentrated in the surface of siliceous materials. On the other hand, round blocks of iron phases can be isolated and also viewed immersed in the glassy matrix, as it is observed in Figure 1(a).

The X-ray diffraction pattern of the volcanic pyroclastic mixture (PM) indicates the presence of an absolute majority of a vitreous amorphous phase, whereas the PT samples is also characterized by a very low resolution. However, the XRD pattern of the dark-ST material, shown in Figure 2, reveals the presence of crystalline phases. X-ray diffraction lines can be correlated to siliceous phases in the form of substituted calcium plagioclase $\left(\mathrm{CaAl}_{2} \mathrm{Si}_{2} \mathrm{O}_{8}\right)$ and pyroxene $\left(\mathrm{Mg}_{2} \mathrm{Si}_{2} \mathrm{O}_{6}\right)$ (PDF 89-1463, 85-1740, 88-2377), both showing the stronger peaks in the zone of $\sim 28^{\circ}, \sim 30^{\circ}$ of $2 \theta$ angles. Likewise, iron oxides, observed as weak reflections, can be assigned to binary and/or mixed oxide, for example, magnetite-type structures PDF 80-0390 (more intense lines at $\sim 30^{\circ}, \sim 35^{\circ}$ of $2 \theta$ ) as well as hematite or related phases PDF $89-2810$ (stronger reflections at $\sim 33^{\circ}, \sim 35^{\circ}$ of $2 \theta$ ). For the ST sample, containing the majority of crystalline phases, it is possible to estimate the presence of plagioclase as major phase $(\sim 50$ $60 \%$ ) with $\sim 10-14 \%$ of piroxene, $\sim 10 \%$ of iron oxides, and a low proportion $(<5 \%)$ of $\mathrm{K}$-feldspar, not detected clearly by $\mathrm{XRD}$. The remainder of material is vitreous.

According to the total alkali versus silica diagram (TAS) for the volcanic rocks, shown in Figure 3, obvious signals of fractionation process are observed, whereas ST materials are located in the andesite-type stability field, the PT fragments belong to rhyolite type. Alkali depletion observed in ST samples can be related to the concentration thereof in the melted phase.

Figure 4 shows the spider diagram for the samples obtained from REE trace elements. The REE depletion observed for ST samples (more pronounced for the heavy elements HREE) can be attributed to dissimilar degree of fractionation. This can be associated not only with the chemistry of the source but also with the crystal-melt equilibrium during the magmatic evolution. Partition coefficients are higher with increasing silica content of the melt. Likewise, the $\mathrm{Eu}(\mathrm{II})$ negative anomaly can be attributed to its compatibility with feldspars and silicate species (similar ionic potential for $\mathrm{Eu}(\mathrm{II})$ and alkaline-earth species). So, differences between the fractionation of the light REE (LREE) with respect to HREE may be related to the presence of other silicate species such as pyroxenes and accessory phases. The behavior observed in Figure 4 is similar to that reported for volcanic materials from previous eruptions of the PCCVC [15].

Surface area (BET) of the pyroclastic material (PM) is $2.23 \mathrm{~m}^{2} \mathrm{~g}^{-1}$, while the ST sample presented a relatively lower value $\left(1.73 \mathrm{~m}^{2} \mathrm{~g}^{-1}\right)$. The difference can be attributed to the presence of crystalline phases [16].

The micro-Raman spectroscopy is a useful technique to define the mineralogy of composite materials, becoming a sensor for identifying promptly the species, isolated or embedded in the matrix [17]. Figures 5(a)-5(d) correspond to the Raman spectra of samples collected from various sample spots. The presence of a complex composition mixture is revealed: alkali aluminosilicate, hematite, and magnetite associated with siliceous phases and carbonaceous material dispersed in the glassy matrix. Hence, the Raman spectra cover a wide range of $\mathrm{Na}, \mathrm{K}, \mathrm{Mg}$, and $\mathrm{Ca}$ silicates [18]. Experimental Raman data of Figure 5(a), with lines at about $325,380,530,665,888$, and $999 \mathrm{~cm}^{-1}$, corroborate 


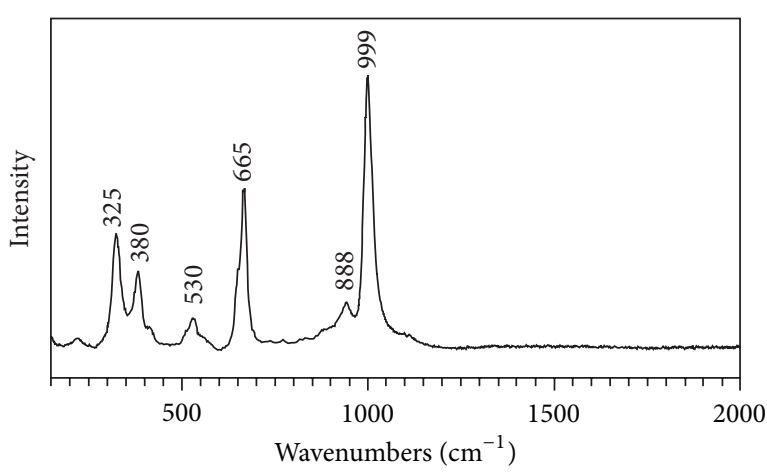

(a)

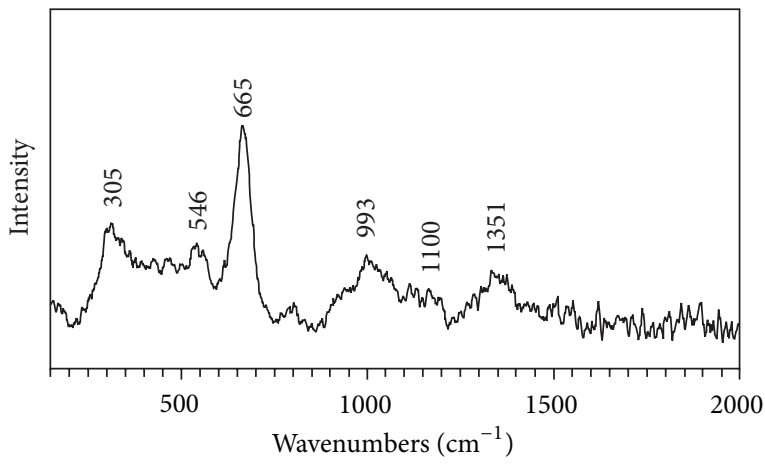

(c)

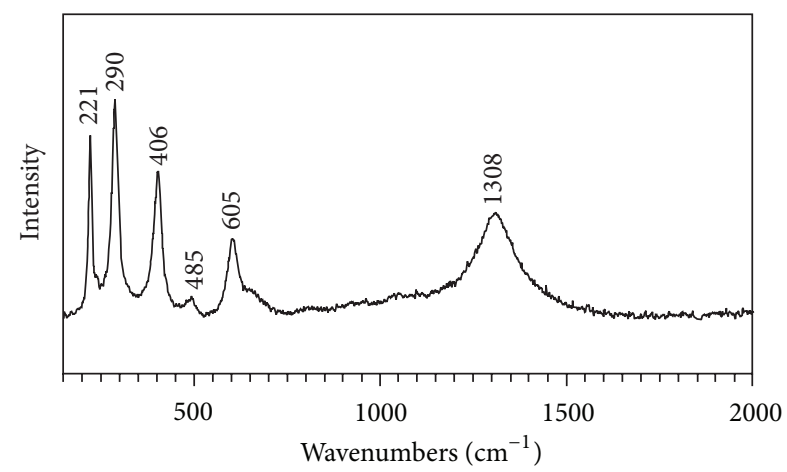

(b)

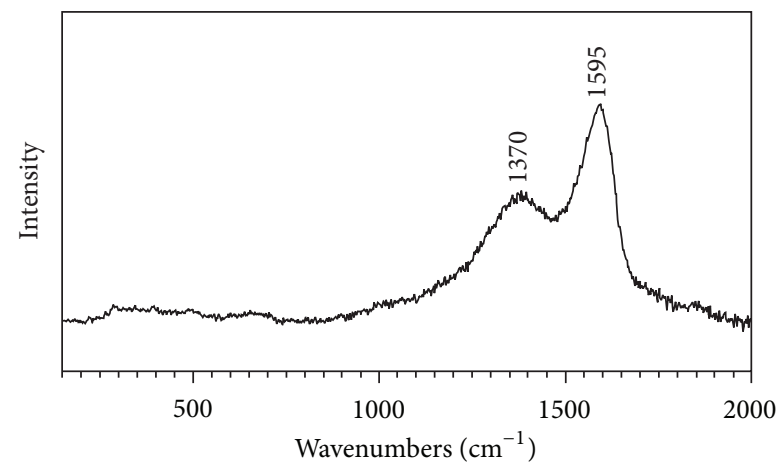

(d)

Figure 5: Micro-Raman spectra registered in different spots (see text).

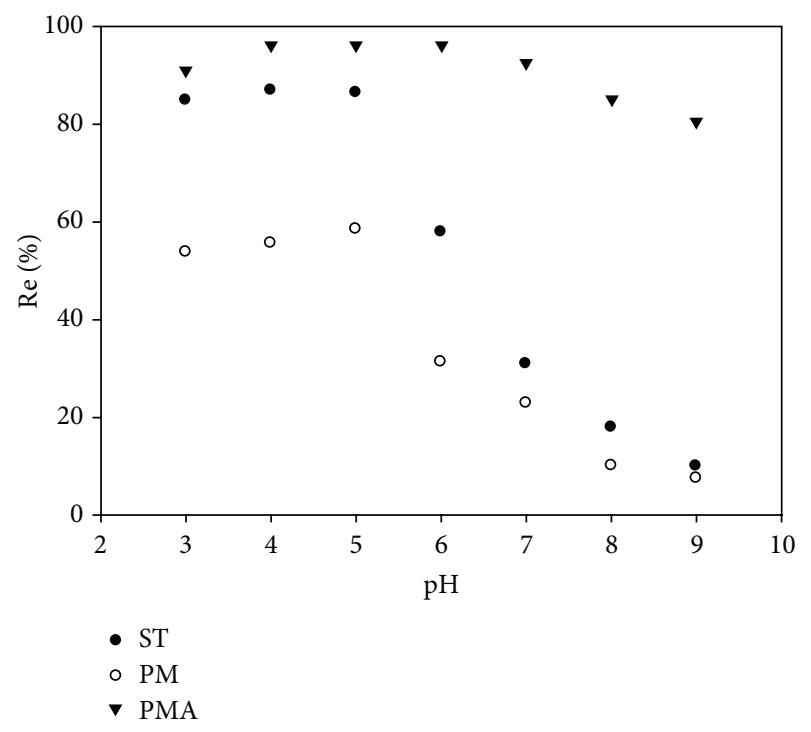

FIGURE 6: Arsenic removal by using volcanic pyroclastic mixture (PM), scoria-type (ST) material, and activated pyroclastic mixture (PMA), at different $\mathrm{pH}$.

the presence of clinopyroxene and plagioclase. The first species is characterized by three strong Raman signals at 322,667 , and $997 \mathrm{~cm}^{-1}$, whereas plagioclase (e.g., anorthite) presents typical strong signal at $510 \mathrm{~cm}^{-1}$ and weak signals in the $1000 \mathrm{~cm}^{-1}$ region [18]. Hematite in natural samples or in any iron oxide mixtures is reliably identified by lines at $\sim 225$, 291, 411, 611, and $1321 \mathrm{~cm}^{-1}$, whereas magnetite shows two weak bands at $\sim 300$ and $\sim 530 \mathrm{~cm}^{-1}$ and an intense signal at $\sim 665 \mathrm{~cm}^{-1}$ which is the most conspicuous and diagnostically useful [17-19].

Spectrum of Figure 5(b) shows bands at 221, 290, 406, 605 , and $1308 \mathrm{~cm}^{-1}$ attributed with hematite phase, whereas a shoulder at $662 \mathrm{~cm}^{-1}$ could be assigned to magnetite.

Likewise, the spectrum of Figure 5(c) is more complex. However, the magnetite presence can be corroborated from the Raman line at $665 \mathrm{~cm}^{-1}$. Other lines at low frequencies (in the range $305-546 \mathrm{~cm}^{-1}$, surely associated with the partial oxidation of magnetite) and between 990 and $1400 \mathrm{~cm}^{-1}(993$, $1100,1351 \mathrm{~cm}^{-1}$ ) usually observed in some plagioclases [18] reveal the strong interaction between phases with different composition and crystal structure. Differences between spectra of Figures 5(b) and 5(c) are surely related to the alteration during the evolution of the eruption process.

Spectrum of Figure 5(d) is characterized by two intense signals centered at 1370 and $1595 \mathrm{~cm}^{-1}$, which can be assigned to active modes of carbon particles (ordered and disordered graphite species, resp.) [20-22]. These seem to be associated to the natural chaoite, mineral species formed by heating graphite at high pressure associated with zircon, rutile, pseudobrookite, and magnetite, among other species. 
3.2. Potentiality in the As Sorption Process. Although the volcanic ash constitutes a significant environmental hazard [23], investigations have been carried out in order to analyze its potential use as raw material in the preparation of adsorbents, cement, and so forth. In this context, the use of ferric impregnated volcanic ash has been proved in the arsenate adsorption process $[12,24]$.

The As content in the PM, PT, and ST studied materials $(12.3,15.7$, and $12.4 \mathrm{ppm}$, resp.) is comparable to that observed in the loess of Argentinean aquifers [13]. However, it was observed that the As was not leached, according to the EPA international method [25]. These aspects were a good signal to prove the capability of the raw material without chemical modification to retain the toxic. On this basis, tentative assays for As removal were done.

The literature reports of adsorption data for ferricimpregnated volcanic ash showed that an increase of $\sim 5 \%$ as $\mathrm{Fe}_{2} \mathrm{O}_{3}$ (by treatment of ferric solution $\left(\mathrm{FeCl}_{3} 20 \mathrm{~g} \mathrm{~L}^{-1}\right)$ ) greatly elevates the $\mathrm{As}(\mathrm{V})$ removal ability by the formation of iron (hydro)oxides [12]. This modification also affects the range of adsorption capability, through an electrostatic attraction as well as surface complexation processes between the As species $\left(\mathrm{H}_{2} \mathrm{AsO}_{4}{ }^{-}, \mathrm{HAsO}_{4}{ }^{-2}\right)$ and iron oxide surface sites $[16,26]$. In our work conditions, the increase of iron content in the activated sample (PMA) can be correlated with a great increase of the surface area $\left(73.69 \mathrm{~m}^{2} \mathrm{~g}^{-1}\right)$.

Figure 6 gives the average values of As adsorbed in the PM, ST, and PMA materials (5.58, 8.92, and $10.40 \% \mathrm{Fe}_{2} \mathrm{O}_{3}$, resp.), at the conditions indicated in the experimental section versus $\mathrm{pH}$. The comparison of the results reveals that the As retention increases with acidity. Maximums of 58.5\%, 87\%, and $96.27 \%$ for PM, ST, and PMA were observed at $\mathrm{pH} \mathrm{5,4}$, and in the 4-6 range, respectively. These acidic conditions can be correlated with those reported in the literature, working with volcanic ash chemically modified with iron [12]. The $\mathrm{pH}$ effect can be attributed to the increase of adsorption sites by surface protons (formation of Fe-O$\mathrm{H}$ and eventually $\mathrm{Al}-\mathrm{O}-\mathrm{H}$ previous to the dealumination process), facilitating the interaction with the $\left(\mathrm{H}_{2} \mathrm{AsO}_{4}{ }^{-}\right.$or $\mathrm{HAsO}_{4}{ }^{-2}$ ) predominant species. This behavior at the surface level shows that arsenate has a direct chemical bond with iron species, with a specific sorption mechanism, following a surface complexation model (inner sphere complexes), as it is widely reported [16].

\section{Conclusions}

The components of the volcanic ash emitted by PCCVC eruption were identified by means of spectroscopic and microscopic techniques, which revealed a mixture of alkali silicates (predominantly glass) and microcrystals of iron oxides (hematite, magnetite), phases of plagioclase type, pyroxene type, and carbonous material. The pyroclastic- and the scoria-type materials, with bulk iron contents of 5.58 and $8.92 \% \mathrm{Fe}_{2} \mathrm{O}_{3}$, have not shown arsenic leaching, retaining the arsenic in solution. On the other hand, the "in situ" chemical modification with a small proportion of iron oxide $(\sim 5 \%$ as $\mathrm{Fe}_{2} \mathrm{O}_{3}$ ) led to a useful adsorbent for arsenic removal from aqueous solution, increasing also the effective range of $\mathrm{pH}$. Comparatively, the good performance can be attributed to the increase of the adsorption sites through the formation of $\mathrm{Fe}$ $\mathrm{O}-\mathrm{H}$ groups. On the basis of physicochemical characterization, the studied ash seems to be an interesting raw material for the arsenic removal, transforming the volcanic waste in a suitable, inexpensive, and abundant adsorbent.

\section{Acknowledgments}

The work was done by financial support of ANPCyT BID 2011 PICT-2186 Argentina and CUIA (Italy-Argentina). Authors thank Mr. R. Viña (LANADI Lab., University of La Plata) and Eng. A. Kang (LIMF Lab., University of La Plata) for technical measurements.

\section{References}

[1] SERNAGEOMIN, 2011, Reportes Especiales de Actividad Volcánica Complejo Volcánico Puyehue-Cordón Caulle, http://www.sernageomin.cl/.

[2] M. E. Canafoglia, M. Vasallo, V. Barone, and I. L. Botto, "Problems associated to natural phenomena: potential effects of the Puyehue Cordon Caulle Volcanic Complex (PCCVC) eruption on the health and the environment in different zones of Villa La Angostura, Neuquen," AUGM-DOMUS, vol. 4, p. 1, 2012.

[3] M. Koshino, "Fertilizers with new functions," in Environmental Conservation and Innovative Fertilization Technologies, T. Yashuda and M. Koshino, Eds., p. 116, Tokyo, Japan, 2001.

[4] B. Langmann, K. Zaksek, and M. Hort, "Volcanic ash as fertilizer," Atmospheric Chemistry and Physics, vol. 10, p. 3891, 2010.

[5] X. Querol, J. C. Umaña, F. Plana et al., "Synthesis of zeolites from fly ash at pilot plant scale. Examples of potential applications," Fuel, vol. 80, no. 6, pp. 857-865, 2001.

[6] V. Zaspalis, A. Pagana, and S. Sklari, "Arsenic removal from contaminated water by iron oxide sorbents and porous ceramic membranes," Desalination, vol. 217, no. 1-3, pp. 167-180, 2007.

[7] J. Giménez, M. Martínez, J. de Pablo, M. Rovira, and L. Duro, "Arsenic sorption onto natural hematite, magnetite, and goethite," Journal of Hazardous Materials, vol. 141, no. 3, pp. 575580, 2007.

[8] W. Driehaus, "Technologies for asenic removal from potable water," in Natural Arsenic in Groundwater, Occurrence, Remediation and Management, J. Bundschuh, P. Bhattacharya, and D. Chandrasekharam, Eds., p. 189, CRC Press-Balkema, Taylor and Francis, London, UK, 2005.

[9] M. Litter, M. Alarcón-Herrera, M. Arenas et al., "Small-scale and household methods to remove arsenic from water for drinking purposes in Latin America," Science of the Total Environment, vol. 429, pp. 107-122, 2012.

[10] WHO, Arsenic. Environmental Health Criteria 18, IPCS International Programme of Chemical Safety, Vammalan Kõirjapaino Oy, Vammala, Finland, 1981.

[11] J. Bundschuh, M. I. Litter, F. Parvez et al., "One century of arsenic exposure in Latin America: a review of history and occurrence from 14 countries," Science of the Total Environment, vol. 429, pp. 2-35, 2012.

[12] R. Chen, Z. Zhang, Y. Yang et al., "Use of ferric-impregnated volcanic ash for arsenate $(\mathrm{V})$ adsorption from contaminated 
water with various mineralization degrees," Journal of Colloid and Interface Science, vol. 353, no. 2, pp. 542-548, 2011.

[13] H. Nicolli, J. Bundschuh, M. Blanco et al., "Arsenic and associated trace-elements in groundwater from the Chaco-Pampean plain, Argentina: results from 100 years of research," Science of the Total Environment, vol. 429, pp. 36-56, 2012.

[14] D. M. Sherman, "Molecular orbital theory of metal-metal charge transfer processes in minerals: Fe(II)-Fe(III) CT and Electron delocalization in mixed valence iron oxides and silicates," Physics and Chemistry of Minerals, vol. 14, no. 4, pp. 355-363, 1987.

[15] R. Daga, S. Ribeiro Guevara, M. L. Sánchez, and M. Arribére, "Source identification of volcanic ashes by geochemical analysis of well preserved lacustrine tephras in Nahuel Huapi National Park," Applied Radiation and Isotopes, vol. 66, no. 10, pp. 13251336, 2008.

[16] Y. Mamindy-Pajany, C. Hurel, N. Marmier, and M. Roméo, "Arsenic adsorption onto hematite and goethite," Comptes Rendus Chimie, vol. 12, no. 8, pp. 876-881, 2009.

[17] S. Das and M. J. Hendry, "Application of Raman spectroscopy to identify iron minerals commonly found in mine wastes," Chemical Geology, vol. 290, no. 3-4, pp. 101-108, 2011.

[18] L. A. Haskin, A. Wang, K. M. Rockow, B. L. Jolliff, R. L. Korotev, and K. M. Viskupic, "Raman spectroscopy for mineral identification and quantification for in situ planetary surface analysis: a point count method," Journal of Geophysical Research E, vol. 102, no. 8, pp. 19293-19306, 1997.

[19] M. Hanesch, "Raman spectroscopy of iron oxides and (oxy)hydroxides at low laser power and possible applications in environmental magnetic studies," Geophysical Journal International, vol. 177, no. 3, pp. 941-948, 2009.

[20] Y. Wang, D. C. Alsmeyer, and R. L. McCreery, "Raman spectroscopy of carbon materials: structural basis of observed spectra," Chemistry of Materials, vol. 2, no. 5, pp. 557-563, 1990.

[21] C. Domínguez and G. Santoro, "Espectroscopía Raman de nanotubos de carbono," Optica Pura y Aplicada, vol. 40, p. 175, 2007.

[22] O. Beyssac, B. Goffé, C. Chopin, and N. Rouzaud, "Raman spectra of carbonaceous material in metasediments: a new geothermometer," Journal of Metamorphic Geology, vol. 20, pp. 859-871, 2002.

[23] C. J. Horwell and P. J. Baxter, "The respiratory health hazards of volcanic ash: a review for volcanic risk mitigation," Bulletin of Volcanology, vol. 69, no. 1, pp. 1-24, 2006.

[24] N. Jaafarzadeh, H. Amiri, and M. Ahmadi, "Factorial experimental design application in modification of volcanic ash as a natural adsorbent with Fenton process for arsenic removal," Environmental Technology, vol. 33, no. 1-3, pp. 159-165, 2012.

[25] US EPA, “Test methods for evaluating solid waste," Method EPA1311: Toxicity Characteristic Leaching Procedure (TCLP) SW-846, Office of Solid Waste and Emergency Response, United States Environmental Protection Agency, Washington, DC, USA, 1990.

[26] H. Guo, D. Stüben, and Z. Berner, "Removal of arsenic from aqueous solution by natural siderite and hematite," Applied Geochemistry, vol. 22, no. 5, pp. 1039-1051, 2007. 

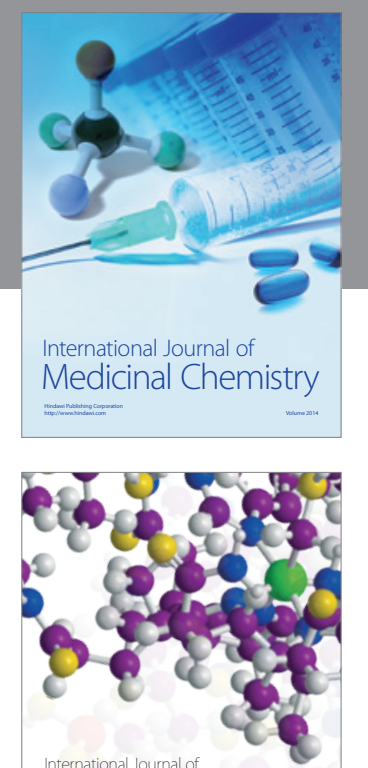

\section{Carbohydrate} Chemistry

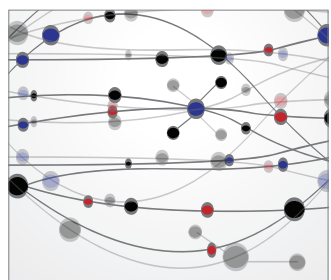

The Scientific World Journal
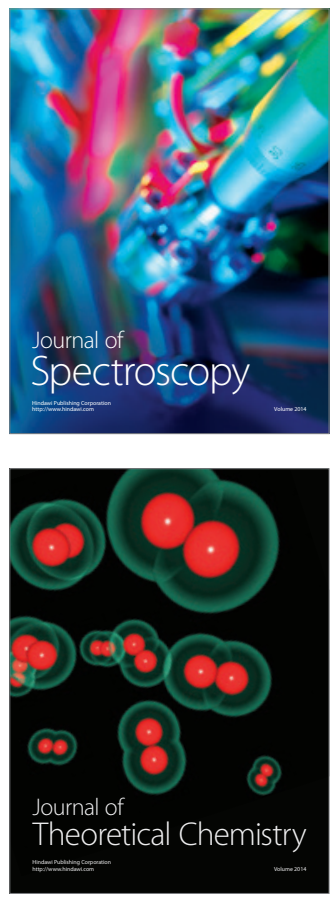
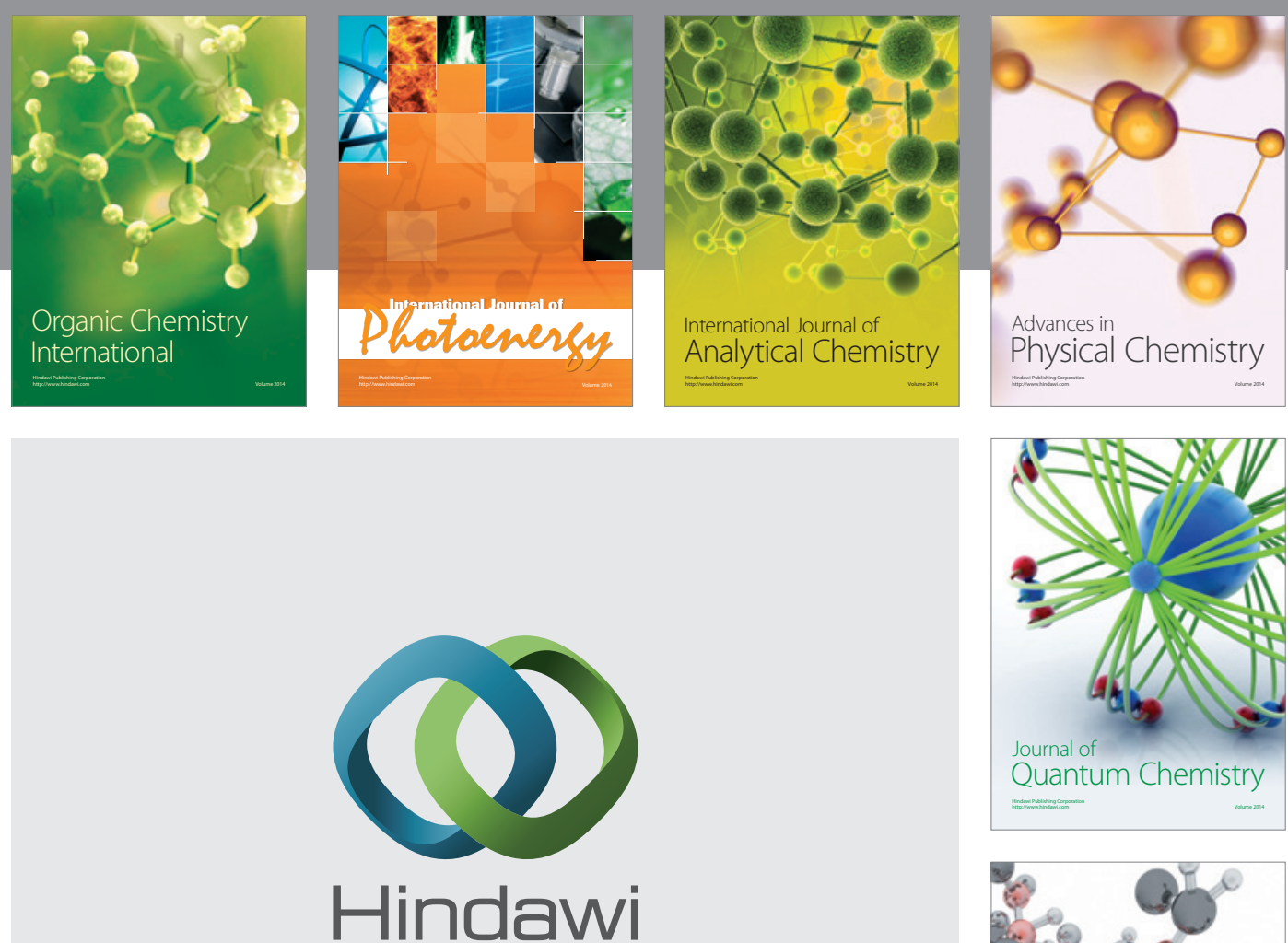

Submit your manuscripts at

http://www.hindawi.com

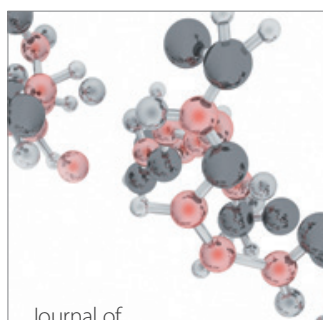

Analytical Methods

in Chemistry

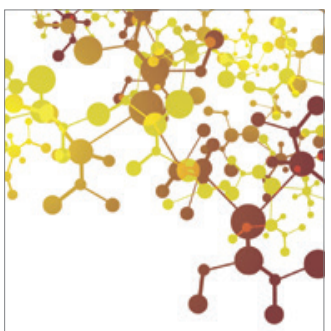

Journal of

Applied Chemistry

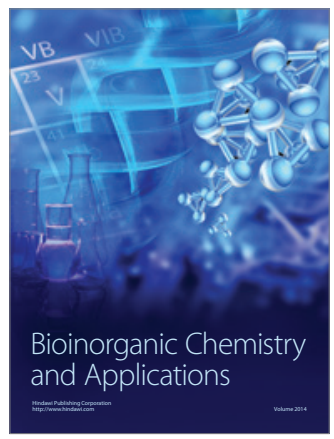

Inorganic Chemistry
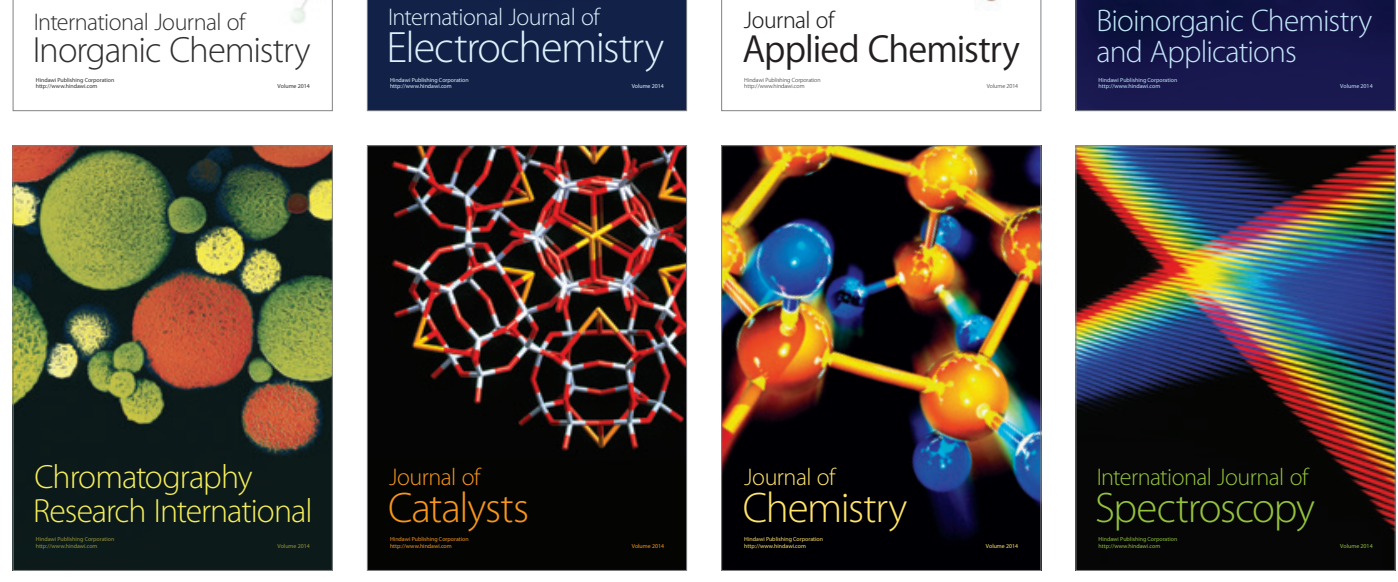